\section{Olivine Hydration in the Deep Upper Mantle: Effects of Temperature and Silica Activity}

\author{
J. R. Smyth ${ }^{1^{*}}$, D. J. Frost ${ }^{2}$, F. Nestola ${ }^{2,3}$, C. \\ M. Holl ${ }^{1}$, and G. Bromiley ${ }^{4}$
}

${ }^{1}$ Department of Geological Sciences, University of Colorado, Boulder, CO 80309 USA.

${ }^{2}$ Bayerisches Geoinstitut, Universität Bayreuth, 95440 Bayreuth, Germany.

${ }^{3}$ Dipartimento di Mineralogia e Petrologia, Università di Padova, Corso Garibaldi 37, I-35137

Padova, Italy.

${ }^{4}$ Department of Earth Sciences, University of Cambridge, Downing Street, Cambridge, CB2 3EQ, UK

Abstract. Although water controls the biology and geology of the surface, hydrogen is perhaps the most poorly constrained compositional variable in the bulk Earth. Its concentration in the upper mantle appears to be controlled by its solubility as hydroxyl in the nominally anhydrous silicate phases, olivine, pyroxene, garnet, wadsleyite, and ringwoodite. Here we describe a series of experiments showing that the solubility of $\mathrm{H} 2 \mathrm{O}$ in olivine at $12 \mathrm{GPa}$ increases with temperature to 8900 ppm by weight at $1250^{\circ} \mathrm{C}$ and decreases at higher temperature with the onset of melting. Sample characterization by infrared spectroscopy indicates that the primary hydration mechanism is the substitution of $2 \mathrm{H}+$ for $\mathrm{Mg} 2+$. Similar results obtained from samples coexisting with clinohumite (low-silica) and with clinoenstatite (high-silica) indicate that silica activity has minimal effect on hydration under these conditions. Single-crystal X-ray diffraction measurements constrain the volume of hydration and indicate significant $\mathrm{M}$-site vacancies. Hydrogen thus appears to become a geochemically compatible element as depths approach $400 \mathrm{~km}$.

\section{Introduction}

The total hydrogen concentration in the Earth is very poorly constrained by geochemical models of accretion and differentiation [Drake and Righter 2001; Abe et al., 2000]. Olivine is the most abundant mineral phase in most models of the upper mantle, so hydrogen uptake by olivine has been a major subject of investigation. Natural olivines contain only up to about 420 ppmw $\mathrm{H}_{2} \mathrm{O}$, but typically contain 100 ppm or less
[Matsyuk and Langer, 2004; Bell and Rossman, 1992; Bell et al., 2004]. Hydrous olivines synthesized at pressures up to $13 \mathrm{GPa}$ may contain considerably more, up to 1510 ppmw $\mathrm{H}_{2} \mathrm{O}$ at $12 \mathrm{GPa}$ and $1100{ }^{\circ} \mathrm{C}$ [Kohlstedt et al., 1996]. Recalculating this amount based on a more recent specific calibration of olivine [Bell et al., 2003], we get about 3500 ppmw $\mathrm{H}_{2} \mathrm{O}$ in this sample, but this specific calibration was developed for polarized infrared spectra, and the spectra of Kohlstedt et al. [1996] are not polarized. Based on this calibration, Mosenfelder et al. [2006] report up to 6400 ppmw in Fe-bearing olivine synthesized at 12GPa and 1100 ${ }^{\circ} \mathrm{C}$ in equilibrium with enstatite, but did not investigate the effects of silica activity or temperature at 12 GPa. Silica activity may also be an important variable as IR spectra are rather different for hydrous olivine equilibrated with periclase $(\mathrm{MgO})$ from those with enstatite at pressures below 3 GPa [Matveev et al., 2001, 2005; Le Maire et al., 2004]. Also, forsterite $\mathrm{H}_{2} \mathrm{O}$ contents up to 9000 ppmw are reported at $12 \mathrm{GPa}$ and $1100^{\circ} \mathrm{C}$ in equilibrium with periclase, but much less in olivines equilibrated with enstatite [Locke et al., 2002], thought to be typical of upper mantle compositions. Berry et al. [2005] report FTIR spectra of natural and synthetic Ti-bearing olivines synthesized at low pressures (1.5 GPa) and infer that $\mathrm{Ti}$ defects in olivine control $\mathrm{H}$ contents in the shallow mantle.

Even trace amounts of hydrogen can have a major effect on physical properties such as deformation strength and electrical conductivity [Karato, 1990; 1998; Mei and Kohlstedt, 2000]. Hydrogen contents in excess of 4000 ppm by weight, if present in the Earth's upper mantle, would constitute a significant fraction of the total water budget of the planet [Hirschmann et al., 2005]. In fact, olivine alone could sequester an amount of water nearly equivalent to the entire volume of the ocean in just the upper $410 \mathrm{~km}$ of the mantle. In addition, the amounts that can be incorporated into the nominally anhydrous minerals of the Transition Zone (410-660 km depth) are larger by as much as an order of magnitude [Kohlstedt et al., 1996; Bolfan-Casanova, 2005]. In order to quantify and understand the solubility of $\mathrm{H}$ in olivine at pressures near the $410 \mathrm{~km}$ discontinuity, we have undertaken a series of experiments to synthesize hydrous olivines under various conditions of silica activity and temperature and to characterize the effects on the crystal structure, cell volume, and infrared spectra.

\section{Experimental and Analytical Methods}

Experiments were conducted at $12 \mathrm{GPa}(\sim 360 \mathrm{~km}$ depth), at temperatures from 1100 to $1600{ }^{\circ} \mathrm{C}$, from subsolidus into the supersolidus region, and at different conditions of silica activity. Synthesis experiments were carried out in double-capsule experiments in the 5000-ton multi-anvil press at Bayerisches Geoinstitut. A single hydrous forsterite composition was formulated from reagent $\mathrm{MgO}, \mathrm{SiO}_{2}$, and brucite. To this mixture, ten percent by weight brucite was added for the low silica composition and ten percent talc was added for the high 


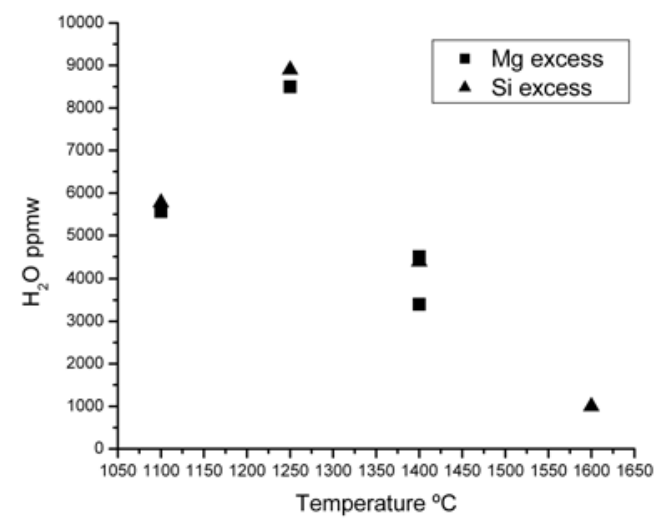

Figure $1 . \mathrm{H}_{2} \mathrm{O}$ contents of forsterite at $1250^{\circ} \mathrm{C}$ as a function of temperature. The decrease above $1250^{\circ} \mathrm{C}$ is consistent with $\mathrm{H}_{2} \mathrm{O}$ dilution in the increasing proportion of melt. The errors on determination are estimated at about 500 ppmw.

silica composition. The two compositions were welded into separate inner Pt capsules and packed with brucite in a welded outer $3.5 \mathrm{~mm}$ capsule. One experiment was conducted with a Fe-bearing composition whereas the remaining runs were with Fe-free compositions. Double capsule experiments were conducted in 18-8 assembly in the 5000 -ton press. The last experiment at $1600^{\circ}$ was conducted as a single-capsule experiment in a 1200-ton press.

Crystalline phases were identified by Raman spectroscopy. $\mathrm{H}_{2} \mathrm{O}$ contents were measured by polarized
FTIR spectroscopy on X-ray-oriented, faceted, single crystals based on the calibration of Bell et al. [2003]. Phases identified and olivine $\mathrm{H}_{2} \mathrm{O}$ contents are summarized in Table 1. Unit cell parameters were refined by singlecrystal X-ray diffraction. In these measurements, the crystals were centered in a four-circle X-ray diffractometer and eight to ten reflections were centered in each of eight octants and unit cell parameters along with crystal positions and angle zeros refined from the angle parameters. Unit cell parameters are given in Table 2 along with parameters for an anhydrous pure forsterite synthesized at $1600{ }^{\circ} \mathrm{C}$ and one atmosphere. $\mathrm{H}_{2} \mathrm{O}$ contents of olivines at both silicaactivity conditions are plotted as a function of temperature in Figure 1.

The results at $1100^{\circ} \mathrm{C}$ are consistent with previous studies [Kohlstedt et al., 1996; Mosenfelder et al., 2006], but we observe an increase in $\mathrm{H}$ content of olivine up to 8900 ppmw at $1250{ }^{\circ} \mathrm{C}$ and a decrease at higher temperatures. Further, we observe similar $\mathrm{H}$ contents and FTIR spectra in olivines equilibrated with both clinoenstatite and clinohumite, so it appears that silica activity in this range has little effect on the substitution mechanism under these conditions. We observe a systematic expansion of the unit cell volume with hydration and are able to estimate a volume of hydration in the quenched samples. We observe similar amounts of $\mathrm{OH}$ and similar FTIR absorption features in Fe-bearing samples, indicating that substitution mechanisms in forsterite may be significant in the deep upper mantle. The decrease in $\mathrm{H}$ content of olivine observed at temperatures above $1250{ }^{\circ} \mathrm{C}$ is likely due to the increasing proportion of partial melt.

\section{Table 1. Synthesis conditions}

\begin{tabular}{|c|c|c|c|c|c|c|c|c|}
\hline Sample & $P$ & $\mathrm{~T}$ & Starting Composition & Olivine & Pyroxene & Humite & $\mathrm{ppmwH}_{2} \mathrm{O}$ & Grain size $(\mu \mathrm{m})$ Comment \\
\hline SZ0407A & 12 & 1250 & $\mathrm{Fo}_{86} \mathrm{Fa}_{04} \mathrm{En}_{05} \mathrm{Fs}_{01} \mathrm{Tc}_{10}$ & $\mathrm{Fo}_{97} \mathrm{Fa}_{3}$ & $\mathrm{En}_{97} \mathrm{Fs}_{03}$ & & 4883 & $50-250$ \\
\hline SZ0407B & 12 & 1250 & $\mathrm{Fo}_{86} \mathrm{Fa}_{04} \mathrm{Pc}_{05} \mathrm{Wu}_{01} \mathrm{Bc}_{10}$ & $\mathrm{Fo}_{97} \mathrm{Fa}_{3}$ & & $\mathrm{ClHm}$ & 8000 & $50-250$ \\
\hline SZ0408A & 12 & 1250 & $\mathrm{Fo}_{80} \mathrm{En}_{10} \mathrm{Tc}_{10}$ & $\mathrm{Fo}_{100}$ & $\mathrm{En}_{100}$ & & 8900 & $50-250$ \\
\hline SZ0408B & 12 & 1250 & $\mathrm{Fo}_{80} \mathrm{Pc}_{10} \mathrm{Bc}_{10} \mathrm{Fo}_{100}$ & & & $\mathrm{ClHm}$ & 8500 & $20-100$ \\
\hline SZ0409A & 12 & 1100 & $\mathrm{Fo}_{80} \mathrm{En}_{10} \mathrm{Tc}_{10}$ & $\mathrm{Fo}_{100}$ & $\mathrm{En}_{100}$ & & & Very Fine Grained \\
\hline SZ0409B & 12 & 1100 & $\mathrm{Fo}_{80} \mathrm{Pc}_{10} \mathrm{Bc}_{10}$ & $\mathrm{Fo}_{100}$ & & $\mathrm{ClHm}$ & 5560 & $20-150$ \\
\hline SZ0410A & 12 & 1400 & $\mathrm{Fo}_{80} \mathrm{En}_{10} \mathrm{Tc}_{10}$ & & & \multicolumn{2}{|c|}{ Chon, Clhm } & 20-100 Inner Capsule broken \\
\hline SZ0410B & 12 & 1400 & $\mathrm{Fo}_{80} \mathrm{Pc}_{10} \mathrm{BC}_{10}$ & $\mathrm{Fo}_{100}$ & & $\mathrm{ClHm}$ & 4503 & $50-250$ \\
\hline SZ0411A & 12 & 1100 & $\mathrm{Fo}_{80} \mathrm{En}_{10} \mathrm{Tc}_{10}$ & $\mathrm{Fo}_{100}$ & $\mathrm{En}_{100}$ & & 5770 & $50-250$ \\
\hline SZ0411B & 12 & 1100 & $\mathrm{Fo}_{80} \mathrm{Pc}_{10} \mathrm{BC}_{10}$ & & & & & 20-100 Inner Capsule broken \\
\hline SZ0501A & 12 & 1400 & $\mathrm{Fo}_{80} \mathrm{En}_{10} \mathrm{Tc}_{10}$ & $\mathrm{Fo}_{100}$ & $\mathrm{En}_{100}$ & & 4400 & $20-120$ \\
\hline SZ0501B & 12 & 1400 & $\mathrm{Fo}_{80} \mathrm{PC}_{10} \mathrm{Bc}_{10}$ & $\mathrm{Fo}_{100}$ & & $\mathrm{ClHm}$ & 3400 & $50-250$ \\
\hline $\mathrm{H} 2296$ & 12 & 1600 & $\mathrm{Fo}_{80} \mathrm{En}_{10} \mathrm{Tc}_{10}$ & $\mathrm{Fo}_{100}$ & & & 1000 & $10-100$ \\
\hline
\end{tabular}

Abbreviations: Fo forsterite, Fa fayalite, En enstatite, Fs ferrosilite, Tc Talc, Pc periclase, Bc brucite, ClHm clinohumite, Chon chondrodite 
The melt phase appears as a fine-grained matt of quench crystals. Although thin sections or polished sections of the charges were not prepared because of the need to preserve large crystals for polarized infrared spectroscopy, we estimate from optical observation of the charges that the percentage of melt phase to be about ten percent at $1400{ }^{\circ} \mathrm{C}$, rising to more than 50 percent at $1600{ }^{\circ} \mathrm{C}$. Aqueous and silicate melt phases are completely miscible under these conditions [Bureau and Keppler, 1999], and in no case was there evidence of an aqueous fluid phase separate from the melt phase, although liquid water was observed to be released on piercing of the inner capsules in the experiments at 1100 and $1250^{\circ} \mathrm{C}$.

Representative polarized FTIR spectra from Fe-free (equilibrated with clinoenstatite) and Fe-bearing (equilibrated with clinohumite) olivine samples are given in Figure 2. Qualitatively, the spectra of the forsterite samples from silica-poor and silica-rich compositions at all temperatures are quite similar and broadly similar to previous FTIR spectra for hydrous olivines quenched from pressures above 5 GPa [Kohlstedt et al., 1996; Mosenfelder et al., 2006]. The E//a spectra show strong absorbance peaks at 3612 and $3578 \mathrm{~cm}^{-1}$; E//b has a sharp feature 3578 and much broader peak at $3552 \mathrm{~cm}^{-1}$; and $E / / c$ at $3566 \mathrm{~cm}^{-1}$ (Fig. 1.). Strong absorbance in this frequency range is consistent with protonation of the octahedral edges [Libowitzky, 1999]. Octahedral edges in the olivine structure range from 2.85 to $3.33 \AA$ except for edges shared with the tetrahedron, which are about

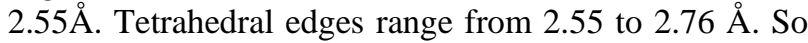
the strong absorbance features of these spectra are more consistent with protonation of the octahedral edges than of the tetrahedral edges. In the hydrated natural sample, there do appear to be minor broad absorption features in the $3400-3200 \mathrm{~cm}^{-1}$ range (Fig $1 \mathrm{~b}$ ) that may be due to protonation of the tetrahedral edge, possibly associated with minor Ti substitution in the octahedra. These features are similar in magnitude to those previously observed [Bell et al., 2003, Lemaire et al., 2004; Berry et al., 2005], but insignificant relative to the very large features at 3400 to $3620 \mathrm{~cm}^{-1}$. Although Lemaire et al. [2004] attribute these peaks to protonation of edges of vacant tetrahedra, correlation of stretching frequency with O-O distance [Libowitzky, 1999] is inconsistent with protonation of tetrahedral edges unless they are locally greatly distended by a tetrahedral cation vacancy.

Atom position and occupancy refinements from single-crystal X-ray data show full occupancy in the anhydrous sample but less than full occupancies in both M1 and M2 sites and also the possibility of some tetrahedral vacancy. Occupancy refinements are very sensitive to positional disorder, and the refinements of hydrous samples all show atomic displacement parameters about 20\% larger than those of the anhydrous sample. Polarization of $\mathrm{O}-\mathrm{H}$ stretching modes may also be used to infer proton locations. The largest peak in the pattern is at $3612 \mathrm{~cm}^{-1}$ and is strongly polarized in the $a$-direction. This frequency corresponds to protonation of an O-O distance of $>2.8 \AA$ [Libowitzky, 1999], and is consistent with the O1-

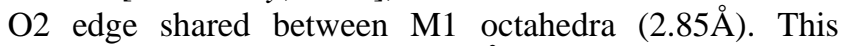
would place the proton about $1.0 \AA$ from O1 at about $x / a=$ $0.95 ; y / b=0.04 ; z / c=0.25$. There is also the possibility of

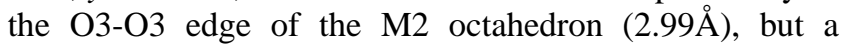
proton on this edge would need a strongly bent $\mathrm{O}-\mathrm{H}-\mathrm{O}$ angle to be consistent with polarizations. Similarly, the peak at $3566 \mathrm{~cm}^{-1}$ in the $c$-direction is consistent with protonation of the unshared O1-O2 edge of the M1 octahedron, but less likely possibilities include the shared (2.76 $\AA$ ) and unshared (3.38 $\AA$ ) O3-O3 edges of M2. The absorptions polarized in the $a$ - and $b$-directions at $3578 \mathrm{~cm}^{-}$ ${ }^{1}$ could correspond to the unshared O1-O3 edge of M1 $(2.84 \AA)$ and less likely possibilities include an unshared O3-O3 edge of M2 (2.99 $\AA$ ). Thus, the very strong absorbance features in the FTIR spectra appear to correspond to protonation of octahedral edges, and polarizations are more consistent with protonation of M1 octahedral edges than of M2 edges. This means that the dominant substitution mechanism for olivine hydration is $2 \mathrm{H}^{+}$for $\mathrm{Mg}^{2+}$.

We have used the olivine calibration of Bell et al. [2003] for integrated FTIR absorption which gives $\mathrm{H}_{2} \mathrm{O}$

\section{Table 2. Unit Cell Parameters and $\mathrm{H}_{2} \mathrm{O}$ contents of Synthetic Forsterites}

\begin{tabular}{|c|c|c|c|c|c|c|c|c|c|}
\hline & Anhyd $\mathrm{Fo}_{100}$ & SZ0408A & SZ0408B & SZ0410B & SZ0411A & SZ0409B & SZ0501A & SZ0501B & H2296 \\
\hline Syn Temp $\left({ }^{\circ} \mathrm{C}\right)$ & 1600 & 1250 & 1250 & 1400 & 1100 & 1100 & 1400 & 1400 & 1600 \\
\hline $\mathrm{H}_{2} \mathrm{O}($ ppmw) & $<10$ & 8900 & 8500 & 4500 & 5770 & 5560 & 4400 & 3400 & 1000 \\
\hline$a(\AA)$ & $4.75518(18)$ & $4.75454(39)$ & $4.75465(39)$ & $4.75574(17)$ & $4.75659(36)$ & $4.75517(46)$ & $4.75463(48)$ & $4.75554(42)$ & $4.7557(10)$ \\
\hline$b(\AA)$ & $10.19853(22)$ & $10.20675(75)$ & $10.20416(75)$ & $10.20383(58)$ & $10.20096(65)$ & $10.20481(66)$ & $10.19925(55)$ & $10.19955(115)$ & $10.1977(16)$ \\
\hline$c(\AA)$ & $5.98215(22)$ & $5.98625(39)$ & $5.98494(39)$ & $5.98383(51)$ & $5.98258(48)$ & $5.98640(38)$ & $5.98346(39)$ & $5.98350(43)$ & $5.9821(8)$ \\
\hline $\operatorname{Vol}\left(\AA^{3}\right)$ & $290.107(17)$ & $290.503(31)$ & $290.373(31)$ & $290.376(27)$ & $290.286(29)$ & $290.494(32)$ & $290.165(33)$ & $290.226(42)$ & $290.115(94)$ \\
\hline
\end{tabular}



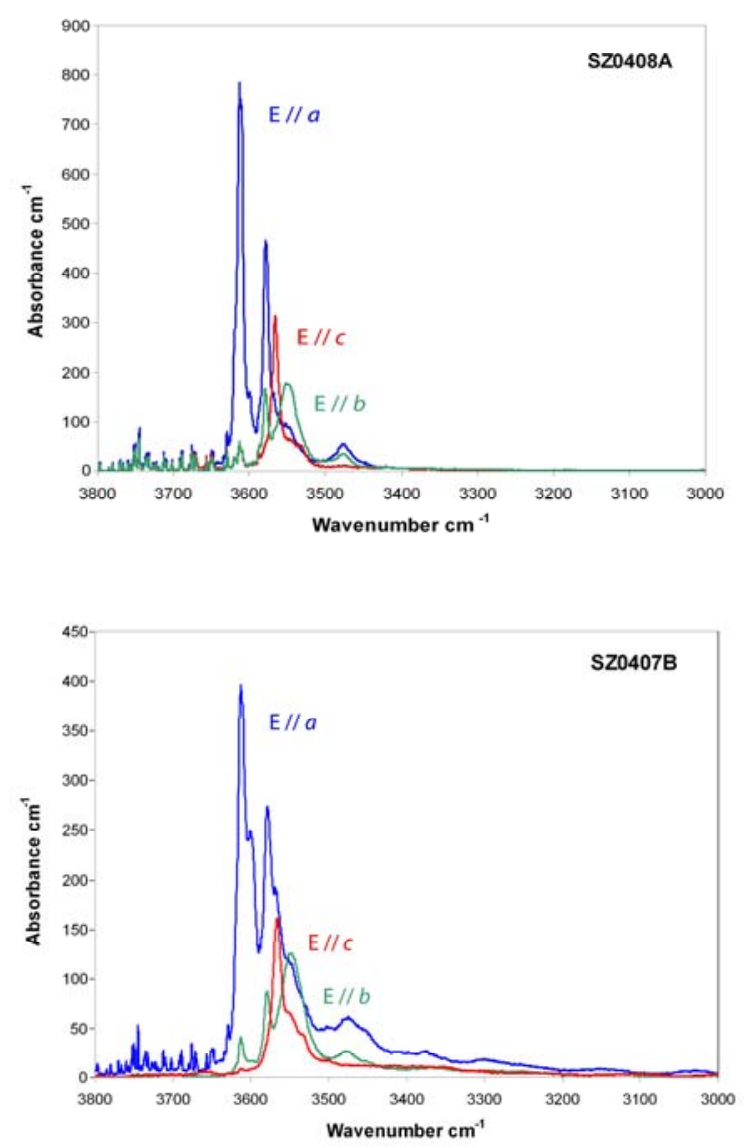

Figure 2. A. Polarized FTIR spectra of hydrous forsterite sample SZ0408A synthesized at $12 \mathrm{GPa}$ and $1250^{\circ} \mathrm{C}$ in equilibrium with enstatite and melt. Integration of the spectrum indicates an $\mathrm{H}_{2} \mathrm{O}$ content of 8900 ppmw $\mathrm{H}_{2} \mathrm{O}$.

(B) Polarized FTIR spectra of hydrous $\mathrm{Fo}_{97}$ sample SZ0407B synthesized at $12 \mathrm{GPa}$ and $1250^{\circ} \mathrm{C}$ in equilibrium with clinohumite and melt. Integration of the spectrum indicates an $\mathrm{H}_{2} \mathrm{O}$ content of 8000 ppmw $\mathrm{H}_{2} \mathrm{O}$.

contents about three times those obtained from the general calibrations of Libowitzky and Rossman [1997] and Paterson [1982]. The calibration of Bell et al. [2003] was obtained from natural samples with a maximum $\mathrm{H}_{2} \mathrm{O}$ content of about 220 ppm by weight, so its use here requires an extrapolation of about a factor of 40. Although the peaks observed by Bell et al. [2003] appear in our patterns, the intensity ratios are quite different. It is possible that this calibration may not be linear or that the calibration over estimates the $\mathrm{H}$ concentration, however since the calibration was developed specifically for olivine, it appears to be the best available.

It is clear from Table 2 that hydration causes an increase in the unit cell volume, and the data allow an estimate of the volume of hydration (Fig. 3). The scatter in the plot may be due to the different diffractometers used on the different samples and it may be partly due to uneven $\mathrm{H}$ distributions in the samples. The infrared

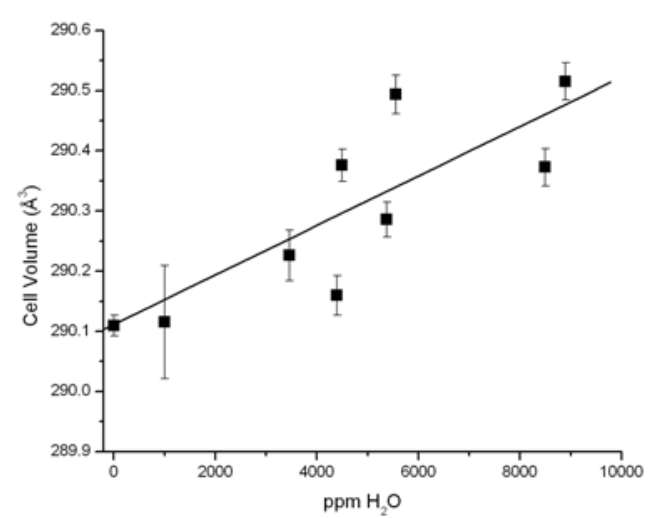

Figure 3. Unit cell volume of forsterite as a function of $\mathrm{H}_{2} \mathrm{O}$ content. Error bars on cell volume are internal precision and do not include systematic error. The line is a linear regression fit to the data as given in the text.

spectra could not be measured on the same crystals used for cell parameter refinement, although no significant variation in $\mathrm{H}$ contents were noted between different samples from the same capsule. Linear regression fit to the observed data gives

$$
\mathrm{V}=290.107+5.5 \times 10^{-5} *\left(\mathrm{H}_{2} \mathrm{O}\right)
$$

with a correlation coefficient of 0.83 , where $\mathrm{V}$ is cell volume in $\AA^{3}$ and $\mathrm{H}_{2} \mathrm{O}$ is the ppm by weight $\mathrm{H}_{2} \mathrm{O}$ as determined from FTIR [Bell et al., 2003]. A linear extrapolation of this equation to the hypothetical end member $\mathrm{H}_{2} \mathrm{MgSiO}_{4}\left(152,000\right.$ ppmw $\left.\mathrm{H}_{2} \mathrm{O}\right)$ in the olivine structure would have a cell volume of $298.5 \AA^{3}$ and a density of $2635 \mathrm{~kg} / \mathrm{m}^{3}$. Although we do not yet have an equation of state for the hydrous samples, it is clear that this volume expansion is significant. Comparing the volume increase to thermal expansion [Fei, 1995], the

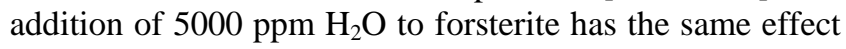
on density as raising the temperature by about $240^{\circ} \mathrm{C}$ at zero pressure. Also, the effect of hydration on volume is similar in magnitude to that of Jacobsen et al. [2005] for wadsleyite, which supports the calibration of Bell et al. [2003] for $\mathrm{H}$ in olivine and is consistent with an octahedral vacancy substitution mechanism in both structures.

\section{Discussion}

Water storage capacities of the upper mantle have been estimated based on a maximum $\mathrm{H}_{2} \mathrm{O}$ concentration in olivine of 5000 ppmw near $410 \mathrm{~km}$ depth [Hirschmann et al., 2005; Bolfan-Casanova, 2005]. However, the current experiments predict water saturation (storage capacity) of the nominally anhydrous phases of a pyrolite upper mantle would rise from $1000 \mathrm{ppmw}$ at $100 \mathrm{~km}$ to more than 5000 ppmw at $410 \mathrm{~km}$, or more than $8000 \mathrm{ppmw}$ if the pyroxenes are able to accommodate $\mathrm{H}$ contents similar to olivine [Hirschmann et al., 2005]. Integrated over the upper mantle we infer that the storage capacity of the 
nominally anhydrous phases in the upper $410 \mathrm{~km}$ of the mantle would exceed two ocean volumes of water. Although storage capacities at the lower temperatures of subduction zones would be less, olivine may still provide a significant conduit by which water can be conducted into the deep mantle. The hot mantle wedge above the subducting slab would be able to trap significant amounts of water emanating from the dehydrating slab. Hydration of olivine in the wedge would greatly reduce its strength [Karato, 1998; Mei and Kohlstedt, 2000], enabling it to flow and conduct dissolved $\mathrm{H}_{2} \mathrm{O}$ into the deeper mantle.

Our run compositions are close to an olivine bulk composition so that we observe more that 90 percent of olivine in the coarsely crystalline phases. Other possible phases such as Phase E and periclase were not observed in the Fe-free runs. Further, we observe no evidence of the proposed modified hydrous olivine structure [Kudoh, 2002] in our single crystal characterizations of the run products. We were, however, able to estimate the $\mathrm{H}_{2} \mathrm{O}$ content of the clinoenstatite at somewhat less than 1000 ppm based on a general calibration [Libowitzky and Rossman, 1997]. It is curious to note that a mantle with about 5000 ppmw $\mathrm{H}_{2} \mathrm{O}$ would exceed saturation on upwelling convection at about $220 \mathrm{~km}$, near the bottom of the low velocity zone [Masters and Shearer, 1995], or lower concentrations at shallower depths [Reichert et al., 2005]. Mierdel et al. [2006] report a spike in H solubility in aluminous orthopyroxene to nearly $10000 \mathrm{ppmw}$ between 1.2 and 1.8 GPa, sharply decreasing at higher pressure which they propose might define the top of the low velocity zone.

Another potentially significant result of this work is that olivine with up to 8900 ppmw $\mathrm{H}_{2} \mathrm{O}$ can coexist with a fluid/melt phase at $1250{ }^{\circ} \mathrm{C}$, and that implied distribution coefficients for $\mathrm{H}$ between olivine and melt may be greater than 0.05 . Whereas most lithophile elements have a well defined ionic radius, which controls its geochemical behavior, $\mathrm{H}$ does not, so its behavior may be dramatically affected by pressure. This means that the geochemical compatibility of $\mathrm{H}$ is likely to be a strong function of pressure and temperature, increasing with depth much more rapidly than that of other trace elements. Dehydration of solid phases by melt extraction will therefore be much less efficient at pressures above $5 \mathrm{GPa}$ so that geochemical studies based on the incompatibility of $\mathrm{H}$ being close to that of $\mathrm{Ce}$ and $\mathrm{K}$ [Dixon et al., 2002] may not be applicable to melting at higher pressures. These results further imply that the efficiency of dehydration by melt extraction on subduction will likely be less efficient than previously estimated [White, 2002].

Because olivine is the most abundant phase in the upper mantle, these results have interesting implications from atomic to global scales. First, single-crystal X-ray structure refinement and FTIR spectra indicate that the principal substitution mechanism at these temperatures and pressures and both compositions is $2 \mathrm{H}^{+}$for $\mathrm{Mg}^{2+}$.
The proton does not actually reside at the $\mathrm{Mg}$ cation position, but rather protonates an oxygen on the edge of the vacant octahedron. Second, from the unit cell parameter refinements, we obtain a quantitative measure of the volume of hydration of olivine at ambient conditions. Third, the results imply that the geochemical compatibility of $\mathrm{H}$ dramatically increases with both pressure and temperature so that the efficiency of slab dehydration on subduction will be much less than previous estimates. Fourth, the results indicate that the $\mathrm{H}$ storage capacity of the nominally anhydrous phases of the upper mantle may be up to twice previous estimates [Hirschmann et al., 2005). Finally, very large potential $H$ contents in olivine in the upper mantle are consistent with a deep water cycle in the Earth whereby a large, deep reservoir in the Transition Zone may exchange water with the surface reservoir via $\mathrm{H}$ dissolved in olivine. Ocean volume may thus represent a dynamic equilibrium with a larger reservoir in the interior incorporated as hydroxyl into solid silicates.

\section{Acknowledgment}

The authors thank D. C. Rubie, S.D. Jacobsen, and M.M. Hirschmann for useful discussions. A detailed review of the manuscript by J.L. Mosenfelder is gratefully acknowledged. Financial support of this study was provided by the U.S. National Science Foundation (grant EAR 03-36611 to JRS), the Bayerisches Geoinstitut Visitors Program, and the Alexander von Humboldt Foundation.

\section{References}

Abe, Y., E. Ohtani, T. Okuchi, K. Righter, and M. J. Drake, (2000) Water in the early Earth. Origin of the Earth and Moon (eds Canup, R. M. and Righter, K.) University of Arizona Press, Tucson, 413-433.

Bell, D. R. and G. R. Rossman, (1992) Water in the Earth's mantle: Role of nominally anhydrous minerals. Science, 255, 1392-1396.

Bell, D., G. Rossman, J. Maldener, D. Endisch and F. Rauch (2003) Hydroxide in olivine: a quantitative determination of the absolute amount and calibration of the IR spectrum: $J$. Geophys. Res., 108, doi: 10.1029/2001JB000679.

Bell, D. R., G. R. Rossman, and R. O. Moore (2004) Abundance and partitioning of $\mathrm{OH}$ in a high pressure magmatic system: Megacrysts from the Monastery kimberlite, South Africa. J. Petrol, 45, 1539-1564.

Berry, A. J., J. Hermann, H. StC. O’Neill, and G. J. Foran, (2005) Fingerprinting the water site in mantle olivine. Geology, 33, 869-872.

Bolfan-Casanova, N. (2005) Water in the Earth's mantle. Mineral. Mag., 69, 229-257.

Bureau, H., and H. Keppler (1999) Complete miscibility between silicate melts and hydrous fluids in the upper mantle; experimental evidence and geochemical implications. Earth Planet. Sci. Lett., 165, 187-196.

Dixon, J. E., L. Leist, C. Langmuir, and J. G. Schilling (2002) Recycled dehydrated lithosphere observed in plumeinfluenced mid-ocean-ridge basalt. Nature, 420, 385-389. 
Drake M. J. and K. Righter (2002) Determining the composition of the Earth. Nature, 416, 39-44.

Fei, Y. (1995) Thermal expansion. Mineral Physics and Crystallography: A Handbook of Physical Constants. AGU Washington, 29-44 (1995).

Hirschmann, M. M., C. Abaud, and A. C. Withers, (2005) Storage capacity of $\mathrm{H}_{2} \mathrm{O}$ in nominally anhydrous minerals in the upper mantle. Earth Planet. Sci. Lett., 236, 167-181.

Karato, S.-I. (1990) The role of hydrogen in the electrical conductivity of the upper mantle. Nature, 347, 272-273.

Karato, S.-I. (1998) Plastic deformation of silicate spinel under transition-zone conditions of the Earth's mantle. Nature, 395, 266-269,

Kohlstedt, D. L., H. Keppler, and D. C. Rubie, (1996) The solubility of water in $\alpha, \beta$ and $\gamma$ phases of $(\mathrm{Mg}, \mathrm{Fe})_{2} \mathrm{SiO}_{4}$. Contrib. Mineral. Petrol., 123, 345-357.

Kudoh, Y. (2002) Predicted models for hydrous modified olivine (HyM- $\alpha$ ). Phys. Chem. Minerals, 29, 387-395.

Lemaire, C., S. C. Kohn, and R. A. Brooker (2004) The effect of silica activity on the incorporation mechanisms of water in synthetic forsterite: a polarized infrared spectroscopic study. Contrib. Mineral. Petrol., 147, 48-57.

Libowitzky, E. (1999) Correlation of O-H stretching frequencies and $\mathrm{O}-\mathrm{H}$. . .O hydrogen bond lengths in minerals. Monatsh.Chemie, 130, 1047-1059.

Libowitzky, E. and G. R. Rossman (1997) An IR absorption calibration for water in minerals. Am. Mineral., 82, 11111115.

Locke, D. R., J. R. Holloway, and R. Hervig (2002) Oxidation independent solution mechanism for hydrogen in olivine: examples from simple and peridotite systems. Eos Trans. AGU, 83(47), Abstractt T21C-1116.

Masters, T. G. and P. M Shearer (1995) Seismic models of the Earth: Elastic and anelastic. Global Earth Physics: A Handbook of Physical Constants, AGU Washington, 88103.

Matsyuk, S. S. and K. Langer (2004) Hydroxyl in olivines from mantle xenoliths in kimberlites from the Siberian platform. Contrib. Mineral. Petrol., 147, 413.437.

Matveev, S., H. StC. O’Neill, C. Ballhaus, W. R. Taylor, and D. H. Green (2001) Effect of silica activity on OH- IR spectra of olivine: implications for low $a-\mathrm{SiO}_{2}$ mantle metasomatism. J. Petrology, 42, 721-729.

Matveev, S., M. Portnyagin, C. Ballhaus, R. A. Brooker, and C. A. Geiger (2005) FTIR spectrum of phenocryst olivine as an indicator of silica saturation in magmas. J. Petrology, 46, 603.614.

Mei, S. and D.L. Kohlstedt (2000) Influence of water on plastic deformation of olivine aggregates, J. Geophys. Res., 105, 21,457-21,481.

Mierdel, K., H. Keppler, J. R. Smyth, and F. Langenhorst (2006) The origin of the Earth's asthenosphere. Nature (in revision).

Mosenfelder, J. L., N. I. Deligne, P. D. Asimow, and G. R. Rossman (2006) Hydrogen incorporation in olivine from 212 GPa. Am. Mineral., 91, 285-294.

Paterson, M. S. (1982) The determination of hydroxyl by infrared absorption in quartz, silicate glasses, and similar materials. Bulletin de Minéralogie, 105, 20-29.
Rychert, C. A., K. M. Fischer, and S. Rondenay (2005) A sharp lithosphere-asthenosphere boundary imaged beneath eastern North America. Nature, 436, 542-545.

White W. M. (2002) Through the wringer. Nature, 420, 366-367. 